\title{
EVALUASI PROGRAM PELAKSANAAN UJIAN ONLINE DENGAN MENGGUNAKAN LEARNING MANAGEMENT SYSTEM MOODLE BERBASIS ANDROID DI SMK NEGERI 1 JAKARTA
}

\author{
Rian Laksana Putra ${ }^{1}$, Arris Maulana², Tuti Iriani \\ 1,2, 3 Universitas Negeri Jakarta \\ 1ianlaksanaputra@,gmail.com, ${ }^{2}$ arrismaulana@unj.ac.id, ${ }^{3}$ tutiiriani@unj.ac.id \\ Diterima : 22 Agustus 2018 \\ Direvisi : 26 Januari 2019 \\ Diterbitkan : 28 Januari 2019 \\ DOI $\quad: \underline{\text { https://doi.org/10.21009/ipensil.v8i1.8483 }}$
}

\begin{abstract}
This study aims to determine whether the Evaluation Program of Testing Online by use Learning Management System Moodle android-based for students Program field DPIB (Desain Permodelan dan Infromasi Bangunan) class X at SMKN 1 Jakarta has been successful or not.Begins research in april 2013 until mei 2013. The method used is the evaluative research method with the type of CIPP evaluation model (context, input, process, product) with a sample of 30 students. Validity test results, 12 items questionnaire is valid. While the results of reliability test, R11 V alue is 0,747. To access the online testing program, head of IT requires program of Moodle, Computer for server, internet networks, and android. The curriculum used is 2013. The average value of an android-based online exam for midterms for students is 81, while for the final school examinations is only 74, lower than the Minimum Completion Criteria (KKM) that has been set which is 75 while the midterm examination score is greater than the value (KKM) From the calculation of the questionnaire, percentage of successful online testing program is only $67.33 \%$ of the respondent. During the implementation of the Android-based online exam program there are still problems, lack of connectors to belp chager android phones so that they are closer and reduce student activity during the exam and there is no Google blocking for exam security and internet connection 1 mbps. The impact of the online exam program that is felt by the school is the teacher and students can save their time in the implementation of the exam compared to using paperles and the internet as a means of evaluating learning. Thus, overall the implementation of an android-based online exam program at SMKN 1 Jakarta can be said to be almost successful, but there is a need for improvement especially in online exam program support facilities.
\end{abstract}

Keywords: Evaluasi, CIPP, testing Online, android

\section{Pendahuluan}

Perkembangaan teknologi informasi dan komunikasi dari masa kemasa semakin mempermudah kebutuhan manusia. Seiring dengan perkembangan zaman teknologi semakin berperan dan bermanfaat hampir disemua bidang, termasuk bidang pendidikan.

Menurut Warsita (2008:150-151), secara umum ada 3 pemanfaatan teknologi informasi atau instruksional computer dan internet untuk pendidikan dan pembelajaran. Pertama, Learning about computers and the internet, yaitu Komputer dapat dijadikan sebagai objek pembelajaran, misalnya ilmu Komputer (computer science). Kedua, Learning with computers and the internet, yaitu teknologi informasi memfasilitasi pembelajaran sesuai dengan kurikulum yang berlaku di sekolah. Ketiga, Learning through computers and the internet, yaitu mengintegrasikan pengembangan keterampilan-keterampilan berbasis teknologi informasi dengan aplikasi-aplikasi dalam kurikulum.

Melalui pemanfaatan Teknologi Informasi dan Komunikasi ujian dapat dilakukan menggunakan media komputer 
atau android untuk ujian online berbasis komputer mengacu pada dasar hukum peraturan BNSP nomor: 0032/P/BNSP/III/2015 tentang juknis UN CBT tahun pelajaran 2014/2015.

Berkembangnya teknologi komputer dan android, instrumen hasil belajar dapat didesain dan diadministrasikan dengan menggunakan pangkalan data. Semua dapat dikontrol dengan mudah dengan memaksimal kan penggunaan.

Menurut Arli (2014) secara sederhana, e-learning adalah memindahkan proses belajar-mengajar secara konvensional kepada dunia maya atau internet. Umumnya, aplikasi yang digunakan adalah web-based. Pada sistem E-Learning menggunakan Learning Management System (LMS) Moodle. Sistem tersebut dimuat dihalaman website dengan domain tertentu, sehingga dapat melakukan proses ujian online, penyimpanan nilai dan penilaian hasil pembelajaran secara online. Penilaian hasil ujian online hanya dapat diakses oleh server tentu nya yang terkoneksi jaringan internet.

SMK bidang keahlian teknologi dan rekayasa serta teknologi informasi dan komunikasi, salah satu nya jurusan teknik gambar bangunan. Berdasarkan hasil prasurvey penggunaan LMS Moodle berbasis android di SMKN 1 Jakarta diantara nya:

1. Pelaksanaan uji coba di mulai pada awal 2016 sampai sekarang 2018 ujian online berbasis android.

2. Hampir semua peserta didik memilki handphone android.

3. Menimalisasi penggunaan anggaran dalam setiap pelaksanaan ujian semester dan tengah semester.

4. Memanfaatkan fasilitas komputer yang ada di sekolah sehingga bisa digunakan untuk server ataupun user.

\section{Identifikasi Masalah}

Berdasarkan uraian latar belakang yang telah dikemukakan sebelumnya, terdapat beberapa permasalahan yang dapat diidentifikasi dalam memfokuskan 4 aspek sebagai berikut:
1. Context. Latar belakang dan tujuan program pelaksanaan ujian online menggunakan LMS moodle berbasis android di SMKN 1 Jakarta.

2. Input. Perencanaan program pelaksanaan ujian online menggunakan LMS moodle berbasis android di SMKN 1 Jakarta.

3. Process: Penerapan program pelaksanaan ujian online menggunakan LMS moodle berbasis android di SMKN 1 Jakarta, khusus nya pada mata pelajaran Ilmu Ukur Tanah, kelas X DPIB.

4. Product. Hasil dan maanfaat penerapan program pelaksanaan ujian online menggunakan LMS moodle berbasis android di SMKN 1 Jakarta.

\section{Pembatasan Masalah}

Program Pelaksanaan ujian online dengan menggunakan LMS moodle berbasis android yang merupakan kebijakan baru dalam dunia pendidikan dan telah berjalan selama 3 (tiga) tahun di sekolah SMKN 1 Jakarta, namun belum banyaknya referensi strandar ujian online menggunakan android, oleh karena itu peneliti membatasi masalah di tempat, yaitu:

1. SMKN 1 Jakarta pada siswa kelas $\mathrm{X}$ Program Desain Permodelan dan Informasi Bangunan.

2. Mata Pelajaran Dasar Kompetensi Kejuruan, Ilmu Ukur tanah.

3. Model yang di gunakan evaluasi CIPP, jadi yang akan dibuat adalah Context (C), Input (I), Process (P), Product (P) untuk menilai pada pelaksanaan ujian online menggunakan LMS moodle berbasis android yang sekolah SMKN 1 Jakarta terapkan.

\section{Rumusan Masalah}

Berdasarkan identifikasi masalah dan pembatasan masalah, maka masalah dapat dirumuskan sebagai berikut:

1. Context. Bagaimanakah latar belakang dan tujuan program pelaksanaan ujian online menggunakan LMS moodle berbasis android di SMKN 1 Jakarta? 
2. Input. Bagaimanakah perencanaan program pelaksanaan ujian online menggunakan LMS moodle berbasis android di SMKN 1 Jakarta?

3. Process: Bagaimanakah penerapan program pelaksanaan ujian online menggunakan LMS moodle berbasis android di SMKN 1 Jakarta, khusus nya pada mata pelajaran Ilmu Ukur Tanah, kelas X DPIB?

4. Product: Bagaimanakah hasil dan maanfaat penerapan program pelaksanaan ujian online menggunakan LMS moodle berbasis android di SMKN 1 Jakarta?

\section{Kegunaan Hasil Penelitian}

Hasil dari penelitian ini diharapkan dapat mengetahui bagaimana kekurangan dan kelebihan dari pelakasanaan ujian online menggunakan LMS Moodle berbasis android dengan memfokuskan 4 aspek CIPP (context, input, process, product).

\section{Kegunaan Teoretis}

Sebagai tambahan wawasaan dan meningkatkan kemampuan dalam hal perkembangan pendidikan.

\section{Kegunaan Praktis}

1. Sebagai bahan referensi dalam rangka memperbaiki dan meningkatkan proses pelaksanaan ujian online di sekolah tersebut.

2. Sebagai bahan acuan untuk memudahkan dalam memahami kekurangan dan kelebihan dalam proses pelaksanaan ujian online.

3. Sebagai salah satu persyaratan untuk memperoleh gelar sarjana dan bahan referensi untuk penelitian selanjutnya.

\section{Tinjauan Pustaka}

\section{Pengertian Evaluasi Program}

Menurut Undang-Undang Republik Indonesia Nomor 20 tahun 2003 tentang Sistem Pendidikan Nasional Pasal 57 ayat
(1) pengertian evaluasi adalah sesuatu yang dilakukan dalam rangka pengendalian mutu pendidikan secara nasional sebagai bentuk akuntabilitas penyelenggara pendidikan kepada pihak-pihak yang berkepentingan diantaranya terhadap peserta didik lembaga dan program pendidikan.

Menurut Tayibnapis (2008:9) mengemukakan bahwa program adalah segala sesuatu yang dicoba lakukan seseorang dengan harapan akan mendatangkan hasil atau pengaruh.

Kegunaan evaluasi program menurut Widoyoko (2012:4) ada empat kegunaan utama evaluasi program pembelajaran diantaranya Menyampaikan program kepada publik serta memberikan informasi bagi pembuat keputusan agar program yang ada menjadi lebih baik serta meningkatkan partisipasi.

Manfaat evaluasi program menurut Arikunto dan Safruddin (2004).

1. Menghentikan program

2. Merevisi program

3. Melanjutkan program

4. Menyebar luaskan program

Dalam penelitian ini evaluasi program yang di maksudkan adalah kegitaaan untuk mengetahui pelaksaan ujian online dengan menggunakan LMS berbasis android di SMKN 1 Jakarta khusus nya di Jurusan Desain Permodelan dan Informasi Bangunan.

\section{Evaluasi Model CIPP (Context, Input, Proces and Product).}

Model evaluasi ini merupakan model yang paling banyak dikenal dan diterapkan oleh para evaluator. Evaluasi model CIPP dapat diterapkan dalam berbagai bidang seperti manajemen, pendidikan, teknik dan sebaagainya. Model CIPP yang dikenal oleh Stufflebeam (Wirawan 2012:92), yang lebih dipaparkan berupa suatu proses untuk memperoleh dan menyediakan informasi yang berguna untuk menilai alternatif keputusan, model CIPP meliputi hal- hal sebagai berikut:
a) Evaluasi Context 
Evaluasi konteks bertujuan untuk memeriksa apakah tujuan dan prioritas yang ada menyesuaikan diri dengan kebutuhan siapapun yang harus dilayani.

b) Evaluasi input

Evaluasi input bertujuan untuk menilai kesiapan pihak sekolah dari segi software dan bardware yang digunakan untuk server mau pun user, sumber daya manusia yang mengawasi (operator), pembiayaan, supply energy yang dibutuhkan termasuk ketika terjadi pemutusan aliran listrik secara mendadak, ketersediaan dan kesiapan soal test yang akan digunakan, serta waktu pelaksanaan, penjadwalan, serta sarana dan prasarana yang mendukung bagi penyelenggara untuk melaksanakan ujian online.

c) Evaluasi process

Evaluasi process bertujuan untuk menilai praktek pelaksanaan Ujian online berbasis android yang dilakukan.

d) Evaluasi product

Evaluasi product bertujuan untuk mengetahui keberhasilan program pelaksanaan ujian online yang telah dilaksanakan.

\section{Pengertian Ujian Online}

Menurut Dewi (2012) secara umum dikatakan online adalah bila ia terkoneksi/terhubung dalam suatu jaringan ataupun sistem yang lebih besar.

Menurut Winarto dan Yunus (2010) mengemukakan bahwa ujian online merupakan proses yang digunakan untuk mengukur aspek-aspek tertentu dari informasi, yang digunakan untuk serangkaian tujuan di lingkungan dimana penilaian itu dilakukan melalui komputer yang terhubung dengan jaringan, kebanyakan penilaian tersebut merupakan tipe dari evaluasi pembelajaran di dunia pendidikan.

Kenneth (2010) mengemukakan bahwa ujian online dapat meningkatkan standar ujian siswa sedangkan system ujian tradisional dengan menggunakan pena dan kertas membutuhkan usaha lebih untuk siswa dan pengawas ujian. Ujian secara manual juga membutuhkan waktu lebih lama karena peserta ujian harus menyiapkan peralatan (buku, pena/pensil, penghapus dsb) untuk mengikuti ujian secara tertib.

Menurut Thurlow, Lazarus, Albus, dan Hodgson dalam Computer-based Testing: Practices and Considerations (2010), ada beberapa manfaat ujian online diantaranya:

1. Administrasi yang efisien

2. Meningkatkan kemampuan peserta ujian

3. Hasil ujian dapat langsung diketahui

4. Pengembangan item soal dapat dilakukan secara efisien

5. Tingkat keaslian/originalitas test dapat ditingkatkan.

\section{Sedangkan dalam Converting to} Computer-Based Testing (2006) yang diterbitkan oleh Professional Testing Inc. menyebutkan tantangan-tantangan dan permasalahan yang dihadapi dalam pelaksanaan ujian online, antara lain:

1. Sumber daya ujian online

2. Bank Soal (Item banks)

3. Metode penyampaian ujian online

4. Penjadwalan ujian online

5. Lokasi ujian online beserta software

6. Pertimbangan keamanan ujian online

7. Menginformasikan pemangku kepentingan ujian online

8. Analisis kelayakan ujian online

\section{Aplikasi LMS Moodle}

Menurut I Kadek dan I dewa (2014) LMS MOODLE adalah perangkat lunak yang di gunakan untuk menyampaikan materi pembelajaran dan resources multimedia secara online berbasis web, mengelola kegiatan pembelajaran serta hasilhasilnya, memfasilitasi interaksi, komunikasi, kerjasama antar pengajar dan peserta didik.

Menurut Peny (2015) dijelaskan bahwa ada beberapa fitur-fitur aplikasi moodle diantaranya:
a) Uploading Bahan kuliah
b) Forum dan Chat
c) Quiz dan Survey 
d) Pengumpulan dan Review Assignments/tugas

e) Penyimpanan Nilai

I Kadek dan I dewa (2014) Kelebihan aplikasi moodle terletak pada sistem jaringan dan juga keamanan yang dapat diatur sendiri untuk ruang akses di batasi oleh luas jaringan yang di buat, serta system pembelajaran fleksibel sesuai kebutuhan user dan banyak fitur yang lengkap. Namun ada kekurangan diantaranya membutuhkan pemahaman yang lebih tentang system yang ada pada moodle, perlu nya kebutuhan tenaga ahli dalam membangun e-learning system ini juga membutuhkan biaya dan memerlukan hardware khusus untuk server maupun user yang memenuhi.

\section{Model Evaluasi Program}

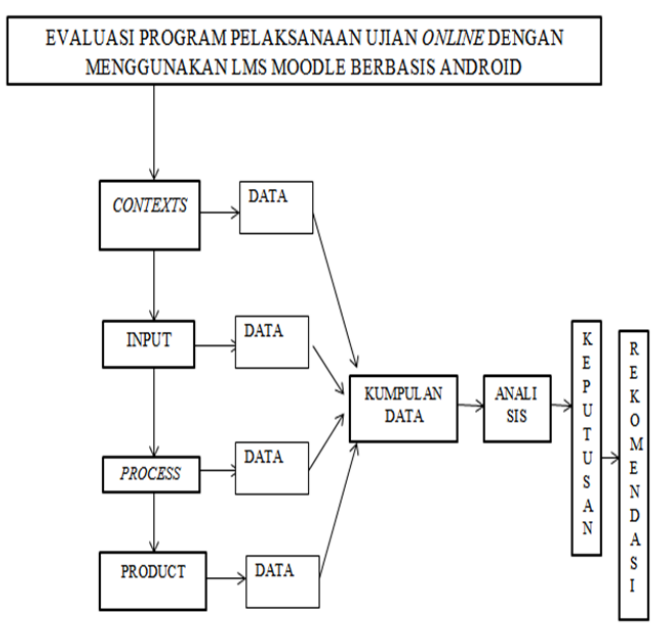

Gambar 1. Desain Penelitian Evaluasi Model CIPP

\section{Tujuan Penelitian}

Tujuan dari penelitian ini adalah untuk mengetahui apakah pelaksanaan ujian online menggunakan system LMS moodle berbasis android dengan evaluasi model CIPP di SMKN 1 Jakarta, pada Program
Keahlian DPIB (Desain Permodelan dan Informasi Bangunan) untuk siswa kelas $\mathrm{X}$ sudah berjalan dengan baik.

\section{Metode Penelitian}

Sekolah yang akan dijadikan tempat penelitian penulis adalah SMKN 1 Jakarta, yang berada di Jl. Budi utomo No. 7 Pasar Baru Kec. Sawah Besar Jakarta Pusat. Waktu penelitian pada bulan April sampai dengan mei 2018.

Penelitian ini merupakan penelitian evaluatif. Penelitian ini menggunakan model pendekatan evaluasi model CIPP (context, input, process, product).

Teknik pengumpulan data pada penelitian ini menggunakan dokumentasi, observasi, ujian online dan dilakukan pula wawancara serta pembagian kuesioner.

Tabel 1. Kriteria Penilaian Instrumen Wawancara

\begin{tabular}{|c|c|c|}
\hline \multirow{2}{*}{ Alternatif Jawaban } & \multicolumn{2}{|c|}{ Pernyataan } \\
\cline { 2 - 3 } & $\begin{array}{c}\text { Positif } \\
(+)\end{array}$ & $\begin{array}{c}\text { Negatif } \\
(-)\end{array}$ \\
\hline Sangat Setuju (SS) & 5 & 1 \\
\hline Setuju (S) & 4 & 2 \\
\hline Ragu-Ragu (R) & 3 & 3 \\
\hline Tidak Setuju (TS) & 2 & 4 \\
\hline $\begin{array}{c}\text { Sangat Tidak } \\
\text { Setuju(STS) }\end{array}$ & 1 & 5 \\
\hline
\end{tabular}

Sumber: (Sugiyono, 2011)

Tabel 2. Kriteria Penilaian Instrumen Observasi

\begin{tabular}{|c|c|}
\hline Penilaian & Nilai \\
\hline Ada & 1 \\
\hline Tidak & 0 \\
\hline
\end{tabular}

\section{Pembahasan Hasil Penelitian}

Tabel 3. Persentase Jawaban Siswa pada Sub Variabel Tujuan dengan Indikator Hasil yang diharapkan

\begin{tabular}{|l|l|l|l|l|l|l|l|}
\hline $\begin{array}{l}\text { SUB } \\
\text { VARIABEL }\end{array}$ & No & Pertanyaan & SS & S & RG & TS & STS \\
\hline
\end{tabular}




\begin{tabular}{|c|c|c|c|c|c|c|c|}
\hline $\begin{array}{l}\text { SUB } \\
\text { VARIABEL }\end{array}$ & No & Pertanyaan & SS & $S$ & RG & TS & STS \\
\hline \multirow{5}{*}{ TUJUAN } & 1 & $\begin{array}{l}\text { Program ujian online } \\
\text { memudahkan saya dalam } \\
\text { mengerjakan soal-soal ujian } \\
\text { bila dibandingkan dengan } \\
\text { menggunakan ujian tertulis }\end{array}$ & $20 \%$ & $36 \%$ & $24 \%$ & $10 \%$ & $2 \%$ \\
\hline & 2 & $\begin{array}{l}\text { Program ujian online } \\
\text { menggunakan android } \\
\text { memudahkan saya dalam } \\
\text { mengerjakan soal-soal ujian } \\
\text { bila dibandingkan ujian online } \\
\text { menggunakan komputer }\end{array}$ & $30 \%$ & $24 \%$ & $39 \%$ & $16 \%$ & $0 \%$ \\
\hline & 3 & $\begin{array}{l}\text { Program ujian online pada } \\
\text { aplikasi moodle lebih } \\
\text { memudahakan saya di } \\
\text { banding dengan aplikasi lain } \\
\text { atau anda hanya pernah } \\
\text { mencoba aplikasi moodle saja }\end{array}$ & $20 \%$ & $44 \%$ & $33 \%$ & $4 \%$ & $0 \%$ \\
\hline & 4 & $\begin{array}{l}\text { Program ujian online dapat } \\
\text { meningkatkan nilai ujian saya } \\
\text { bila dibandingkan dengan } \\
\text { menggunakan ujian tertulis. }\end{array}$ & $5 \%$ & $40 \%$ & $21 \%$ & $18 \%$ & $1 \%$ \\
\hline & 5 & $\begin{array}{l}\text { Saya langsung dapat } \\
\text { mengetahui nilai ujian saya } \\
\text { ketika saya telah selesai } \\
\text { mengerjakan soal ujian online }\end{array}$ & $10 \%$ & $12 \%$ & $27 \%$ & $24 \%$ & $2 \%$ \\
\hline
\end{tabular}

Tabel 4. Hasil Evaluasi Saranan Ujian online berbasis android

\begin{tabular}{|l|l|l|l|}
\hline \multicolumn{1}{|c|}{ SARANA } & $\begin{array}{l}\text { HASIL } \\
\text { OBSERVASI }\end{array}$ & KRITERIA & EVALUASI \\
\hline Komputer & $60 \mathrm{Buah}$ & 20 buah & Sesuai \\
\hline Genset & $\mathrm{Ada}$ & ada & Sesuai \\
\hline Cctv & $\mathrm{Ada}$ & Setiap kelas & Tidak sesuai \\
\hline Wifi & $\mathrm{Ada}$ & Setiap kelas & Tidak sesuai \\
\hline Konektor & $\mathrm{ada}$ & Setiap kelas & Sesuai \\
\hline
\end{tabular}

Penelitian evaluasi program

pelaksanaan ujian online bebasis android menggunakan aplikasi moodle ini sudah berjalan dan keberhasilan program pelaksanaan ujian online bebasis android ini tergantung dari pada sosialiasi guru kepada murid serta fasilitas sekolah yang telah ditunjuk oleh pemerintah provinsi DKI Jakarta sehingga bisa menjadi contoh untuk sekolah yang lain nya di provinsi DKI Jakarta. Dalam penelitian evaluatif ini menggunakan model evaluasi CIPP (Context, input, process, product)

$\begin{array}{cccr}\text { Dalam } & \text { evaluasi } & \text { konteks, latar } \\ \text { belakang } & \text { untuk } & \text { menerapkan } \\ \text { penyuluhan/pengarahan } & \text { yang } & \text { telah }\end{array}$

DKI Jakarta yang telah di hadiri oleh pihak sekolah SMKN 1 Jakarta dan juga untuk mengurangi penggunaan kertas (paperless) untuk ujian UTS dan UAS serta melatih siswa untuk terbiasa dengan ujian berbasis komputer namun sayangnya dokumen khusus penyuluhan dari pemerintah dinas pendidikan DKI Jakarta tidak ada dan hanya berupa pelatihan penggunaan aplikasi moodle pada android maupun computer.

Sedangkan tujuan dari program ujian online berbasis android ini, Mengikuti saran pemerintah dinas pendidikan DKI Jakarta dan Pemanfaat dana yang sudah ada yang di alokasikan di dalam BOP serta 
mempermudah proses pembelajaran dan evaluasi pembelajaran di sekolah.

Dalam evaluasi masukan, kurikulum yang saat ini digunakan yaitu Kurikulum 2013 mendukung adanya program ujian online berbasis android. Sedangkan untuk penyusunan soal ujian dapat diserakan kepada staf IT sehingga guru hanya membuat soal ujian. Kelengkapan fasilitas program ujian online android ini hampir memcukup kebutuhan siswa karena strategi roling jadwal tiap angkatan kelas sehingga dari penggunaan jaringan internet yang cukup stabil.

Dalam evaluasi proses, secara umum proses program pelaksanaan ujian online berbasis android berjalan cukup baik dan lancar karena strategi pengaturan jadwal ujian online jadi solusi agar penggunaan internet cukup dan server tidak down. Sedangkan untuk kondisi ruangan kelas sudah cukup memadai, namun pendingin ruangan tidak berfungsi secara optimal atau terjadi kerusakan sehingga ruangan kelas menjadi panas. Kondisi ruangan ini mempengaruhi kelancaran dan kenyamanan siswa dalam mengerjakan soal ujian online berbasis android.

Dalam evaluasi produk (product evaluation) dapat diketahui bahwa tujuan dari program ini sudah belum sempurna tercapai terutama dalam hal pemanfaatan dana BOP dan teknologi. Dampak positif dari program ujian online ini adalah saat ini hampir semua guru sudah mengerti bagimana fungsi dari penggunaan aplikasi moodle yang akan disosialisasikan kepada siswa dalam konteks hanya pada pengisian soal ujian serta memudahkan guru dalam pembelajaran. Sedangkan, dari hasil perhitungan kuesioner angka $67 \%$ dan berdasarkan hasil ujian nilai siswa uts dan uas, diketahui bahwa prosentase adalah $65 \%$.

\section{Kesimpulan}

Berdasarkan temuan-temuan kondisi di sekolah dan pembahasan hasil evaluasi ujian online yang telah dilakukan selama penelitian dari januari sampai mei Bertempat di SMK NEGERI 1 Jakarta, maka penulis mengambil kesimpulan sebagai berikut:

1. Pada aspek konteks (Context) yang meliputi kebijakan sekolah, ujian online dilaksanakan dengan baik dan juga untuk mempersiapkan kebiasaan siswa terhadap ujian online.

2. Pada aspek masukan (Input) ujian online di SMK NEGERI 1 Jakarta yang meliputi sarana dan prasana, software dan hardware, soal tes dan managemen pelaksanaan sebagian telah memadai dan sesuai dengan kriteria keberhasilan, sebagian pula masih memerlukan tindak lanjut yang lebih mendalam demi tercapainya keberhasilan program pelaksanaan ujian online berbasis android pada tingkat input serta dibarengi dengan dokumen pemerintah yang lengkap.

3. Pada aspek proses (Process), pelaksanaan ujian online berbasis android yang meliputi pengawasan, konsekuensi pelanggaran, system perjokian dan system block google masih kurang pada system block google agar hasil nilai siswa terjamin ke murnian nya.

4. Pada aspek keluaran (product), ujian online dapat mengefisiensikan waktu dalam proses penginputan nilai yang dilakukan oleh staf IT karena tidak harus mengumpulkan kertas jawaban siswa, tidak harus memeriksa setiap lembar jawaban siswa serta hilangnya kekhawatiran siswa akan hilang nya lembar jawaban siswa. Karena setelah mengisi soal nilai akan langsung keluar apabila server langsung menginfokan nilai siswa hari itu juga.

\section{Saran}

1. Untuk keamanan soal sebaiknya dilakukan block google agar siswa tidak mencari jawaban di internet saat ujian berlangsung.

2. Soal test berserta jawaban nya sebaiknya dilakukan validitas pada setiap maple pelajaran di sekolah, sehingga bener - benar 
mengukur kemampuan siswa pada setiap mata pelajaran nya.

3. Hendak nya pihak sekolah melakukan simulasi ujian online berbasis android 1 minggu sebelum pelaksanaan ujian agar memastikan kesiapan siswa maupun pelaksana nya.

4. Hendak nya pengawas mempersiapkan konektor sebelum pelaksaan ujian berlangsung sehingga tidak membuang waktu siswa dan aktivatas ujian berjalan lancar.

5. Kecepatan internet sangat berpengaruh terhadap program ujian online berbasis android. Jika internet lambat maka proses pengisian soal siswa akan terhambat sehingga menghabiskan waktu dalam ujian online, maka dari itu perlu ditingkatkan lagi tingkat kecepatan internet atau di perbanyak jumlah wifi.

\section{Daftar Pustaka}

Arikunto, Suharsimi dan Cepi Safrudin abdul Jabar, 2004. Evaluasi Program Pendidikan, Jakarta: Bumi Aksara.

Bartram, Dave. \& Hambleton, Ronald K. 2006. Computer-Based Testing and the Internet: Issues and Advances. (online) http://books.google.co.id/books?id $=$ FhRbA-

ewhdEC\&pg=PA91\&dq=Compute r-

Based+Testing + and + the+Internet:

+ Issues + and + Advances\&hl $=$ en\&sa

$=$ X\&ei $=2 \mathrm{aC} 6 \mathrm{UfCuFOfw0QGU2I}$

$\mathrm{DACw} \&$ redir_esc $=\mathrm{y} \quad$ [diakses tanggal 4 November 2017 ]

Becker, 2006. Computer-Based Testing and the Internet: Practices and Considerations. (online)

https://scholar.google.co.id/scholar ?q=Becker $+(2006)+$ dalam + Comput er-

based+Testing: + Practices + and + Co nsiderations,\&hl=id\&as_sdt $=0 \&$ as_ vis $=1 \&$ oi $=$ scholart $[$ diakses tanggal 4 November 2017]

BNSP Nomor: 0032/P/BNSP/III/2015 tentang juknis UN CBT (Computer Based Test)

4 - Volume 8, Nomor 1, Februari 2019
I Kadek dan I dewa (2014) E-Learning berbasis moodle. Yogyakarta. Graha ilmu

Iswindarty. Peny (2015) Learning Management System.

http://www.vedcmalang.com/pppp tkboemlg/index.php/menuutama/t eknologi-informasi/1394-lms

[diakses tanggal 4 November 2017 ]

Kenneth. (2010). Intranet Entranet Examination System of Liceo de Cagayan University. Advancing Information Technology Research, Vol. 1 Maret 2010-84.

Okma, Wiranto. \& Mahmud, Yunus. (2010). Rancangan Bangun Sistem Latihan Soal Ujian TOEIC (Test of English For International Communication) Berbasis Web.Jurnal Dinamika Dotcom, Vol.2. No.2.2010205.

Sugiyono. 2011. Metode Kombinasi. Bandung: Alfabeta.

Thurlow, Martha.; Lazarus, Sheryl S.; Albus, Debra.; \& Hodgson, Jennifer. 2010. Computer-based Testing: Practices and Consideration. Synthesis Report 78: 1-4

Tayibnapis, Farida Yusuf. 2008. Evaluasi Program dan Instrumen untuk Program Pendidikan dan Penelitian, Jakarta: PT. Rineke Cipta.

Undang-Undang Republik Indonesia No 20 Tahun 2003 Tentang Sistem Pendidikan Nasional

Warsita, Bambang (2008). Teknologi Pembelajaran: Landasan \& Aplikasinya. Jakarta: Rineka

Widoyoko, Eko Putro. (2012). Evaluasi Program Pembelajaran. Yogyakarta: Pustaka belajar. 